\title{
A inovação disruptiva e a metodologia pré-textos
}

\author{
The disruptive innovation and the pre-texts methodology
}

\author{
Camila Maciel de Oliveira' (1D $\mid$ camilamacieloliveira@gmail.com \\ Mercedes Balcells ${ }^{1,2}$ (1) merche@mit.edu \\ Doris Sommer ${ }^{3}$ (D) dsommer9@gmail.com
}

\section{RESUMO}

Introdução: O relato de experiência descreve o protocolo utilizado em uma das atividades realizadas durante a iniciativa destinada à busca por soluções de impacto em saúde através da inovação disruptiva - “IDEA² Global, Orientação e conexões transformadoras para inovadores em tecnologia médica", em maio de 2019, no Instituto de Engenharia Médica e Ciência, Massachusetts Institute of Technology (IMES MIT).

Relato de Experiência: A metodologia Pré-Textos foi escolhida para estimular a criatividade e instigar a curiosidade inerentes à busca por soluções de problemas complexos, através da leitura de um texto desafiador e atividades relacionadas, em formato de workshop. Reunindo profissionais de vários segmentos e nacionalidades, o período de duas horas e quarenta e cinco minutos foi o tempo dispensado ao workshop inspirado em práticas oriundas de alguns países da América Latina.

Discussão: Por meio da observação participante, constatou-se que os partícipes se mostraram entusiasmos e engajados por atividades "mão na massa", em meio a leitura ativa de um texto sobre conexões neurais em processos criativos. A devolutiva da avaliação sobre o workshop confirmou a impressão dos facilitadores.

Conclusão: A metodologia Pré-Textos é uma estratégia passível de aplicação em grupos heterogêneos, podendo contemplar habilidades como a criatividade e a colaboração. Assim, estimula-se a utilização desta metodologia em outras situações semelhantes.

Palavras-chave: Inovação; Comunicação Interdisciplinar; Metodologia; Educação Médica.

\section{ABSTRACT}

Introduction: The experience report describes the protocol used in one of the activities carried out during the initiative aimed at the search for health impact solutions through disruptive innovation - "IDEA2 Global, Guidance and transforming connections for innovators in medical technology", in May 2019, at the Institute of Medical Engineering and Science, Massachusetts Institute of Technology (IMES MIT).

Experience report: The Pre-Texts methodology was chosen to stimulate creativity and instill the curiosity inherent in the search for solutions to complex problems, through the reading of a challenging text and related activities in a workshop format. Bringing together professionals from various segments and nationalities, the two-hour and forty-five-minute period was the time spent on the workshop inspired by practices from some Latin American countries.

Discussion: Through observation, it was observed that participants were engaged and fascinated by hands-on activities, amid the active reading of a text on neural connections in creative processes. The feedback from the evaluation on the workshop confirmed the facilitators' impression.

Conclusion: The Pre-Texts methodology is a strategy that can be applied in heterogeneous groups and can include skills such as creativity and collaboration. Thus, the use of this methodology should be encouraged in other similar situations.

Keywords: Innovation; Interdisciplinary Communication; Methodology; Medical Education.

\footnotetext{
${ }^{1}$ Institute for Medical Engineering and Science, Massachusetts Institute of Technology, Cambridge, Massachusetts, Estados Unidos.

2 Bioengineering Department, Institut Quimic de Sarria, Ramon Llull Univ, Barcelona, Espanha.

${ }^{3}$ Romance Languages and Literatures and of African and African American Studies, Harvard University, Cambridge, Massachusetts, Estados Unidos.

Editora-chefe: Rosiane Viana Zuza Diniz.

Editor associado: Pedro Tadao Hamamoto Filho.

Recebido em 14/07/20; Aceito em 11/03/21.

Avaliado pelo processo de double blind review.
} 


\section{INTRODUÇÃO}

As várias características que compõem o ser humano geralmente são influenciadas por duas inevitáveis condições. Os fatores genéticos e ambientais são considerados primordiais, não apenas em relação à incidência de doenças, mas também quanto a aspectos relacionado à criatividade' .

Especialmente nos últimos anos, o estudo de genes que determinam a formação de um neurotransmissor chamado dopamina, a descrição de conjuntos de estruturas anatômicas do cérebro responsáveis pela criatividade e pelo ambiente em que o indivíduo se insere tem sido objetos de estudo ${ }^{1,2}$. Isto tem acontecido pela necessidade de compreensão dos mecanismos envolvidos no processo criativo, essencial ao ato de inovar.

A inovação disruptiva - por sua vez - é definida como a transformação de uma tecnologia, produto ou serviço em algo novo, mais simples, conveniente e acessível ${ }^{3}$. De forma complementar, a cocriação tem sido utilizada como estratégia por vários segmentos do mercado, há alguns anos. Por definição, entende-se o verbo cocriar como uma forma de inovar a partir da colaboração, reunindo indivíduos multidisciplinarmente e partes interessadas em busca de um objetivo em comum ${ }^{4}$.

Conceitos como a inovação disruptiva e a cocriação perfazem a iniciativa "Global IDEA², orientação e conexões transformadoras para inovadores em tecnologia médica"5. Já a metodologia Pré-textos tem sido aplicada em situações e públicos distintos sustentada por três principais pilares como o estímulo à inovação em educação, à leitura e à cidadania ${ }^{6}$. Porém, tem sido referido que outras habilidades são passíveis de contemplação dependendo da necessidade e do interesse do grupo ou do direcionamento dado pelo texto e atividades propostas ${ }^{6}$.

Neste relato de experiência, objetivou-se demonstrar como o protocolo da metodologia Pré-Textos foi aplicado em um grupo heterogêneo, incluindo médicos empreendedores, para estimular a criatividade e instigar a curiosidade, durante o primeiro encontro presencial do "IDEA² Global", em 2019.

\section{RELATO DE EXPERIÊNCIA}

O “IDEA² Global, orientação e conexões transformadoras para inovadores em tecnologia médica" é uma iniciativa destinada à busca por soluções de impacto em saúde pela inovação disruptiva. Os projetos são submetidos à apreciação por avaliadores internos e externos à instituição, no início de cada ano (março ou abril). É realizada anualmente por meio de seminários presenciais e remotos e tutorias - no decorrer de seis meses - implementados por pesquisadores do Instituto de Engenharia Médica e Ciência, Massachusetts Institute of Technology (IMES MIT) e mentores parceiros.
O objetivo desta ação é amparar o aprimoramento de projetos previamente iniciados por cientistas empreendedores latinos, americanos e europeus.

Em 2019, a metodologia Pré-Textos ${ }^{6}$ foi uma das atividades escolhidas para o estímulo à criatividade em situações desafiadoras e à experimentação da colaboração durante o "IDEA² Global”. Ambas as habilidades - criatividade e colaboração - seriam fundamentais, nos meses subsequentes, àqueles participantes engajados na solução de problemas complexos e envolvidos no processo de inovação disruptiva.

\section{A metodologia}

O metodologia Pré-Textos foi inspirada em autores brasileiros como Paulo Freire e Augusto Boal e em práticas criadas em algumas culturas da América Latina ${ }^{6}$. Com propostas simples, as diretrizes são explicadas em sua totalidade desde o início do workshop. Para garantir a descontração e o entrosamento, a abertura do workshop sempre acontece com uma atividade denominada quebra-gelo; por exemplo, o arremesso de bolas de papel para a dinâmica de apresentação, como descrito a seguir.

Durante todo o período da realização do workshop, a disposição do grupo em círculo é premissa obrigatória para que todos possam ver e serem vistos. Outras regras são importantes para os momentos de diálogo e reflexão: por exemplo, um participante terá a oportunidade de falar pela segunda vez, se todos já tiverem se manifestado pelo menos uma vez. Outra estratégia interessante que compõe o método é que os "vizinhos" (pessoas do lado de cada participante) sejam checados para se ter a certeza de que todos tenham manifestado seu ponto de vista. O sinal de tempo, gesticulado pelas mãos, pode ser utilizado por qualquer um dos participantes para sinalizar quando a fala de um deles estiver se estendendo além do proposto, pois o sugerido são frases sucintas e diretas.

O material a ser utilizado nas atividades práticas é colocado à disposição em uma mesa ou mesmo no chão com o intuito de descentralizar a fonte e estimular a autonomia, não sendo distribuído ou entregue aos participantes.

Previamente a cada atividade, a seguinte sequência é seguida:

1. a exposição do título e do que inspirou a construção daquela atividade;

2. orientações para a realização daquela prática;

3. o limite de tempo para o desenvolvimento.

Durante a primeira atividade, o texto é lido em voz alta por um dos participantes que tenha se voluntariado para a tarefa, não sendo previamente entregue aos outros. Somente após a leitura é que o texto é disponibilizado para 
os interessados. Geralmente, todos os participantes buscam o texto para a segunda leitura pela preocupação da elaboração adequada do raciocínio que será exposto no círculo de discussão. Apenas alguns poucos minutos são disponibilizados para a leitura individual.

Ao final de cada atividade desenvolvida, todos os participantes compartilham a reflexão sobre o que fora realizado no momento anterior. A reflexão é utilizada para entrelaçar a prática criativa e o pensamento crítico sobre o texto em análise. A discussão é iniciada a partir da frase "o que fizemos?".

\section{A escollha do texto}

O texto é o motivo central (o pretexto) para o desenvolvimento subsequente de todas as outras atividades. A escolha do texto é realizada pelo facilitador, previamente ao workshop, e precisa ser feita de forma cuidadosa, para garantir que o conteúdo seja adequado ao nível intelectual do grupo, de modo que os participantes se sintam desafiados, o que garante o engajamento do leitor/ participante. Não é aconselhável então - que o texto seja fácil ou demasiadamente difícil ${ }^{6,7}$.

Preconiza-se que todos os participantes estejam em padrão de igualdade: que o texto não privilegie ninguém e que o mesmo não tenha sido lido por nenhum integrante previamente.

\section{Descrição das atividades realizadas}

1. O aquecimento (o "quebra-gelo") foi realizado para o estreitamento de relações de forma descontraída. Nesta ocasião, disponibilizamos uma pequena bola de jornal e esclarecemos as regras do jogo: quem recebesse a bola diria o seu nome e a sua profissão. Em alguns minutos, outras bolas foram incluídas na brincadeira - gradativamente. De modo geral, quando várias bolas são lançadas ao mesmo tempo, a atenção dos participantes precisa ser potencializada.

2. A confecção da capa de um livro utilizando materiais recicláveis. Foi uma das maneiras de demonstrar como construir ou reconstruir a partir de materiais disponíveis, mimetizando situações vivenciadas por povos de países em desenvolvimento. Diante da escassez de recursos, a criatividade é desafiada.

3. Leitura do texto realizada simultaneamente ao trabalho manual. Baseamo-nos no pressuposto de que a atenção destinada ao texto nesta condição poderia ser potencializada. Um voluntário fez então - a leitura em voz alta enquanto os colegas dedicavam-se à confecção da capa do livro.

4. Elaboração de perguntas para e a partir do texto. Tem como finalidade engajar o leitor, fazendo com que esse não seja apenas o receptor do conteúdo, mas que participe ativamente do processo de leitura. As perguntas de cada um foram escritas em um papel, lidas em voz alta; depois, penduradas em uma corda. Num segundo momento, todos os participantes dirigiram-se ao cordel e cada um escolheu uma pergunta que gostaria de responder. De volta aos seus lugares, a resposta foi escrita e compartilhada com todo o grupo.

5. Representação por meio de dinâmicas gestuais e corporais. Foi realizada a partir da escolha, em duplas ou trios, de uma expressão contida no texto. Orientamos que os arranjos integrassem pessoas que não se conhecessem previamente. Cada grupo escolheu a expressão do texto que gostaria de imitar; após a escolha e arranjos para a apresentação, enquanto um grupo representava, todos os outros tentavam adivinhar a expressão escolhida.

Pela observação, constatamos o engajamento e o fascínio dos participantes por atividades mão na massa (foto 01), em meio a leitura ativa de um texto sobre conexões neurais em processos criativos ${ }^{2}$. A devolutiva da avaliação sobre o workshop confirmou a impressão dos facilitadores.

\section{Criatividade como habilidade}

Atualmente o mundo requer estratégias para o desenvolvimento de alunos que possam enxergar possibilidades além do óbvio, tanto profissionalmente quanto na vida pessoal $^{8}$, e a metodologia Pré-textos potencialmente influencia tal habilidade. Esta estratégia fora escolhida para ser utilizada no "IDEA² Global" para que os participantes reconhecessem a importância de "pensarem fora da caixa".

Com relação às estruturas cerebrais, a área responsável pela criatividade relacionada à arte é diferente daquela utilizada para a resolução de problemas². Em uma mesma metodologia, geramos estímulos em áreas distintas do cérebro, potencialmente influenciando campos diversos de atuação. Assim, a metodologia Pré-textos contempla dois tipos de processos criativos relacionados à arte e à resolução de problemas - de forma coordenada e simultânea durante todo o seu processo.

Durante os círculos de discussão, a exposição a perspectivas diferentes estimula a geração de ideias criativas ${ }^{9}$. Adicionalmente, a ausência de julgamento por parte dos facilitadores ou de colegas - como regra - contribui para a liberdade de pensamento e de criação, como relatado na literatura9.

Utilizamos as atividades artísticas - a construção de capas de livros simultaneamente à escuta da leitura de um texto desafiador, por exemplo - como gatilho para o estímulo ao pensamento criativo. Por sua vez, as dinâmicas envolvendo 
diferentes expressões corporais, coordenadas em grupo, podem ser consideradas aqui como o produto pela busca por soluções.

Pela análise de diferentes fases de carreiras consideradas criativas, Lu Liu et. al. observaram que, durante o hot streaks de cientistas e artistas, não houve mudança detectável com relação à produtividade, cogitando o papel fundamental de alterações endógenas na criatividade individual neste período ${ }^{10}$. Definiram o termo hot streaks como sendo o momento da vida profissional em que a performance individual é substancialmente superior à sua performance típica, marcada pela fase em que "o ganho gera ainda mais ganho"10.

Algumas das características essenciais para o desenvolvimento do potencial criativo do indivíduo englobam as habilidades intelectuais, como a definição de problemas e o pensamento perspicaz, além da produção de novas ideias e a motivação intrínseca ${ }^{2}$. A cada dia é mais clara a relevância de características específicas conferidas aos cientistas que precisarão enfrentar situações como as pandemias, a pobreza mundial ou as alterações climáticas. A dinamicidade e o pensar "fora da caixa" serão grandes aliados na resolução de problemas complexos impostos por situações inevitáveis como as citadas $^{8,11}$.É essencial que os participantes possam compreender a necessidade do engajamento em times multidisciplinares, do desenvolvimento de habilidades capazes de prever mudanças e de influenciar positivamente colegas que os cercam ${ }^{8}$.

No cenário contemporâneo, a criatividade se faz indispensável para alavancar processos disruptivos. Para isto, incontáveis horas de trabalho entre quatro paredes não serão suficientes.

\section{CONCLUSÕES}

A experiência permitiu reafirmar que não há uma metodologia única para o estímulo ao desenvolvimento de habilidades como criatividade e/ou resolução de problemas; contudo, existem caminhos favoráveis ou potenciais. A experiência relatada usou do método pedagógico Pré-Textos, reconhecido na educação em humanidades, transposta à educação para um grupo multidisciplinar, incluindo médicos empreendedores. A metodologia interroga o aprender, o ensinar, o pesquisar e o ser especialista. Neste relato, pode-se demonstrar que a metodologia Pré-Textos é uma estratégia passível de aplicação em grupos heterogêneos, podendo contemplar habilidades como a criatividade e a colaboração.

\section{CONTRIBUIÇÃO DOS AUTORES}

Camila Maciel de Oliveira: análise e interpretação dos dados, coleta de dados e redação do manuscrito. Mercedes Balcells: supervisão e responsabilidade geral pelo estudo. Doris Sommer: concepção e desenho do estudo, metodologia e validação e revisão crítica do texto.

\section{CONFLITO DE INTERESSES}

Declaramos não haver conflito de interesses.

\section{FINANCIAMENTO}

M.B. foi parcialmente financiada pelo Ministério da Economia da Espanha (SAF2017-84773-C2-1-R), Fundacion Empreses IQS e o Global CoCreation Lab, Inc (Miami, FL).

\section{REFERÊNCIAS}

1. Heilman KM. Possible brain mechanisms of creativity. Arch Clin Neuropsychol. 2016;31(4):285-96.

2. Schuler AL, Tik M, Sladky R, Luft CD, Hoffmann A, Woletz $M$, et al Modulations in resting state networks of subcortical structures linked to creativity. Neurolmage. 2019;195:311-9.

3. Bencke FF, Gilioli RM, Royer A. Inovação disruptiva: uma análise das pesquisas empíricas publicadas no Brasil| Disruptive innovation: an analysis of the empirical research published in Brazil. Revista Brasileira de Gestão e Inovação. 2017;5(2):159-80.

4. Greenhalgh $T$, Jackson $C$, Shaw $S$, Janamian T. Achieving research impact through co-creation in community-based health services: literature review and case study. Milbank Q. 2016;94(2):392-429.

5. MIT. Transformative mentorship and connections for medical technology innovators (IDEA2); 2019. [acesso em 15 mai 2020]. Disponível em: https:// idea2.mitlinq.org/.

6. Sommer D. The work of art in the world: Civic agency and public humanities. Duke University Press; 2013.

7. Rancière J. $O$ mestre ignorante: cinco lições sobre a emancipação intelectual. Autêntica; 2011.

8. Lechler R. Diversity, creativity, and flexibility will be needed from the next generation of medical scientists. Lancet. 2017;389 Suppl 1:S1.

9. Ezzat H, Camarda A, Cassotti M, Agogué M, Houdé O, Weil B, et al. How minimal executive feedback influences creative idea generation. PloS One. 2017;12(6):e0180458.

10. Liu L, Wang $Y$, Sinatra R, Giles $C L$, Song C, Wang D. Hot streaks in artistic, cultural, and scientific careers. Nature. 2018;559(7714):396.

11. Resnick M, Robinson K. Lifelong kindergarten: Cultivating creativity through projects, passion, peers, and play. MIT Press; 2017. 